\title{
MOODLE: PERCEPÇÃO DISCENTE SOBRE AS POTENCIALIDADES DA PLATAFORMA
}

\author{
FLORIANÓPOLIS/SC JULHO/2018
}

\author{
Sabrina Bleicher - IFSC - sabrina.bleicher@ifsc.edu.br \\ Giovana Schuelter - UFSC - giovanas@gmail.com \\ Carlos Alberto da Silva Mello - IFSC - carlos.mello@ifsc.edu.br \\ Douglas Juliani - IFSC - douglas.juliani@ifsc.edu.br \\ Tipo: Investigação Científica (IC) \\ Natureza: Descrição de Projeto em Andamento \\ Categoria: Métodos e Tecnologias \\ Setor Educacional: EDUCAÇÃO SUPERIOR
}

\begin{abstract}
RESUMO
O processo educativo está repleto de componentes digitais que facilitam o ensino e a aprendizagem e este artigo concentra-se em uma das possibilidades tecnológicas disponibilizadas a estudantes e educadores. Pretende-se apresentar as potencialidades oferecidas pelos Ambientes Virtuais de Ensino e Aprendizagem, mais especificamente aqueles suportados pela plataforma Moodle. Com esse objetivo, investigou-se o tema a partir da percepção de estudantes de um curso de especialização à distância. Como resultado foi possível identificar itens relevantes relacionados às potencialidades desse software que foram categorizados em cinco temáticas: (1) usabilidade; (2) interação, (3) aspectos didáticos pedagógicos, (4) registro e gerenciamento da aprendizagem e (5) interface e recursos disponíveis e que podem ser úteis em diversos contextos educacionais que utilizem Ambientes Virtuais de Ensino e Aprendizagem (AVEA).
\end{abstract}

Palavras-chave: Educação a Distância. Moodle. Potencialidades. 


\section{Introdução}

Atualmente, são muitas as ofertas de cursos EaD e o que se percebe é que, geralmente, o diferencial está na qualidade e mediação do processo educativo. Um aliado a tal objetivo é o uso de plataformas digitais de aprendizagem, que possibilitam interação, compartilhamento de materiais diversos e colaboração entre os envolvidos. Com esta perspectiva, este artigo apresenta uma pesquisa sobre as potencialidades da utilização da plataforma Moodle como Ambiente Virtual de Ensino e Aprendizagem (AVEA). Para identificar tais quesitos, foi realizado um questionário com estudantes do curso de pósgraduação em Formação Pedagógica para Docência na Educação Profissional e Tecnológica do Instituto Federal de Santa Catarina (IFSC), curso ofertado integralmente na modalidade a distância. Assim sendo, este trabalho apresenta em seu referencial teórico, aspectos relacionados aos AVEAs e à utilização da plataforma Moodle e, em seguida, relata a avaliação realizada com os estudantes: sua metodologia, os resultados obtidos e as considerações finais.

Destaca-se que este artigo é parte de uma pesquisa em andamento cujos resultados anteriores já foram publicados. O artigo "Moodle como ambiente virtual de apoio a mediação pedagógica: fragilidades percebidas pelo usuário" (SCHUELTER, BLEICHER e MELLO, 2017) apresentou as fragilidades identificadas e encontra-se publicado no Anais do Congresso Internacional de Ambientes Hipermídia para Aprendizagem de 2017. O artigo intitulado "Plataforma Moodle: Fragilidades e possibilidades de melhoria percebidas por estudantes de EaD" (no prelo) complementa o primeiro e destaca, conforme o título introduz, propostas de melhoria sugerida pelos estudantes. No estudo aqui apresentado, devido ao desenvolvimento da análise dos dados coletados, publicamse, no tópico dos resultados e discussão, as potencialidades identificadas por estudantes de EaD que fizeram uso da plataforma Moodle como AVEA.

\section{Referencial teórico}

Atualmente, percebe-se fortemente a utilização das tecnologias em todos os níveis de educação, favorecendo a inovação e qualidade do processo educativo. A apropriação das mídias e Tecnologias de Informação e Comunicação (TIC's) nos processos de ensino e aprendizagem faz ressignificar o conceito de conhecimento. O tempo e espaço já não são mais problemas, proporcionando uma educação sem distância e levando o sistema educacional a assumir um papel, não só de formação de cidadãos pertencentes àquele espaço, mas a um espaço de formação inclusiva em uma sociedade de diferenças (RODINEY, 2018). Observa-se também uma crescente necessidade de inovação e atualização nas práticas educacionais de modo a atender o novo perfil dos 
estudantes, mais tecnológicos. Isso exige que os profissionais da educação busquem constante atualização profissional com educação continuada, de forma que possam conciliar o estudo com as tarefas do dia a dia de trabalho. Para tais demandas, é possível contar com os ambientes virtuais que favorecem tal processo de estudo.

Atualmente podemos contar com os Ambientes Virtuais de Ensino e Aprendizagem, que possuem ferramentas de entrega de conteúdos e ferramentas de interação, como: fórum, chat, envio de mensagem, entre outras. Esta oferta de tecnologias trouxe [...] uma nova forma de executar o processo educativo, possibilitou construções conjuntas de aprendizagem, onde os participantes podem interagir diariamente independente do lugar geográfico que se encontram (SCHUELTER, BLEICHER e MELLO, 2017, p. 3).

Os cursos a distância, em especial, quando utilizam AVEAs, permitem que o estudante vivencie a simultaneidade entre formação e atuação, pois não há necessidade de se afastar do ambiente de trabalho. Os estudantes de formações deste tipo e que ainda não são profissionais ganham também boas alternativas, pois têm a possibilidade de vivenciar o estudo aplicado a sua realidade local ou global, dando uma formação mais ágil e globalizada. Foi justamente a incorporação de tecnologias computacionais de comunicação na educação possibilitou o desenvolvimento de sistemas digitais que integram conjuntos de programas e funcionalidades em uma sofisticada arquitetura computacional possibilitando que plataformas virtuais hospedassem e gerenciassem 0 processo de ensino e aprendizagem realizado virtualmente (FILATRO, 2008).

O Moodle (Modular Object Oriented Distance Learning) é um desses sistemas, sendo visto como um aliado importante no desenvolvimento do ensino a distância. Diferentes referências (SILVA, 2015; ABED, 2017; AGÊNCIA ESTÚDIO SITE, 2017) apontam que - Moodle é um dos sistemas mais utilizados mundialmente, para diferentes níveis educacionais. Umas das facilidades que levam a grande utilização dessa plataforma como AVEA é o fato de ser um software livre, com código aberto. Além disso, possui, no mundo todo, grupos especializados em sua melhoria, favorecendo o crescimento constante do sistema e dando possibilidades de implantação de novas ferramentas para atender as demandas encontradas por instituições que muitas vezes necessitam de funcionalidades específicas. No seu formato de base, o Moodle oferece uma gama de ferramentas que podem ser configuradas de acordo com a situação do curso ofertado. Conforme explicam Oliveira e De Nardin (2012, p. 12): 
Com o referencial brevemente citado, objetivou-se apresentar uma base sobre os temas focos do estudo realizado. A seguir, descrevem-se a metodologia adotada na pesquisa e os resultados encontrados.

\section{Procedimentos metodológicos}

Esta pesquisa buscou identificar potencialidades da plataforma Moodle quando esta é utilizada como suporte para Ambientes Virtuais de Ensino e Aprendizagem em cursos EaD. Para isso adotou-se uma abordagem metodológica do tipo qualitativa - porque buscou compreender e analisar as características apresentadas pelo objeto de estudo e interpretar os dados recolhidos - e exploratória - porque propôs-se a explorar, desenvolver e aumentar o conhecimento existente sobre um determinado tema (GIL, 2008). Para coletar os dados que subsidiaram o estudo, a pesquisa fez uso do conhecimento disponível em publicações acadêmicas de diversos tipos (o que a caracteriza como bibliográfica) e adotou o instrumento "questionário" como forma de coletar a opinião dos usuários sobre o tema estudado.

Um questionário pode ser definido como "uma série ordenada de questões que são submetidas a pessoas com o propósito de obter informações, que devem ser respondidas por escrito e sem a presença do entrevistador" (MARCONI, LAKATOS, 2010, p.86). O questionário desta pesquisa foi aplicado por meio de três perguntas que questionavam o discente participante da pesquisa a responder quais eram as fragilidades, as potencialidades e as proposições de melhoria que observavam em relação a utilização do Moodle como plataforma suporte ao AVEA do curso. As respostas eram abertas e o estudante estava livre para expressar sua opinião.

O questionário foi inserido na prova presencial da componente curricular de "Tecnologias Educacionais" do curso de Pós-graduação Lato Sensu, em nível de Especialização, em Formação Pedagógica para Docência na Educação Profissional e Tecnológica ofertada pelo Centro de Referência em Formação e Educação a Distância (CERFEAD) do IFSC em parceria com o Instituto Federal Fluminense (IFF do Rio de Janeiro). O curso tem duração prevista para 18 meses e carga horária de 560 horas. A oferta em estudo teve seu início em 10 de dezembro de 2015 e o questionário foi aplicado nas datas de 13 de outubro e 03 de novembro de 2016 com os cursistas matriculados na citada componente curricular. Isso significa que a prova presencial aconteceu aproximadamente 11 meses depois do início do curso, portanto, considerouse que os respondentes já tinham, naquele momento, familiaridade e experiência com a plataforma Moodle para contribuir com a pesquisa. O curso contava com 110 alunos inscritos, dos quais 67 realizaram a avaliação presencial e responderam às questões 
propostas. Assim, o percentual de respostas obtidas em relação a amostra total foi de mais de $50 \%$, índice maior que os $25 \%$ previsto e descrito por Gillham (2000), Gil (2008) e Marconi e Lakatos (2010), como o mínimo necessário para considerar a amostra respondente relevante. Destaca-se que a amostra foi definida como "não probabilística por conveniência", ou seja, a escolha dos participantes foi definida por estar acessível e disponível no local e momento em que a pesquisa se realizou.

Embora o questionário aplicado tenha buscado recolher dados a respeito de fragilidades, potencialidades e possibilidades de melhoria para/sobre o uso da plataforma Moodle, neste estudo, conforme já explicitado, apresentam-se apenas os resultados relacionados às potencialidades percebidas pelos usuários. Tal aspecto é abordado no tópico a seguir.

\section{Apresentação e discussão dos resultados}

Uma potencialidade representa o conjunto dos recursos de que uma atividade ou um recurso dispõe; é a capacidade de trabalho, de produção ou de ação que algo ou alguém tem para oferecer (PRIBERAM, [201-]). A intenção desta pesquisa foi identificar esse conjunto de recursos disponíveis que tornam, conforme já descrito, o Moodle uma das plataforma de AVEAs mais utilizadas em todo o mundo, além de identificar também o que os alunos percebiam como mais positivamente relevante em relação ao sistema adotado pelo curso. O questionário aplicado não indicava nenhum tipo de padronização das respostas, em função disso, cada estudante escreveu sobre as potencialidades do AVEA-Moodle de acordo com a sua percepção. Todas as respostas foram compiladas e uma a uma, analisadas. Após a interpretação dos dados, estes foram divididos em quatro grandes temáticas, a saber: (1) usabilidade, (2) interação, (3) aspectos didáticos pedagógicos, (4) registro e gerenciamento da aprendizagem e (5) interface e recursos disponíveis. Respostas similares foram agrupadas em uma única afirmação, o que possibilitou comparar quais potencialidades, na visão dos discentes, eram mais relevantes. Cada uma das figuras a seguir apresenta uma temática específica e expõe, em ordem decrescente, as respostas mais recorrentes entre os estudantes.

A usabilidade refere-se a facilidade de se utilizar um software ou um sistema a fim de se executar uma atividade. Diversos aspectos podem indicar uma boa usabilidade. Em relação ao uso da plataforma Moodle como AVEA, os discentes destacaram que as principais potencialidades de usabilidade referem-se a facilidade que o Moodle dispõe em relação ao acesso independente de hora e local, o que garante mais flexibilidade ao processo de ensino e aprendizagem. Além disso, muitos destacaram que o Moodle é de fácil utilização e uma plataforma com multifuncionalidades, pois permite uso nas 
modalidades presencial e a distância, em cursos de diferentes níveis e tipos e também possibilita o acesso por meio de dispositivos diversos. Todos esses aspectos e também aqueles menos citados estão sistematizados e podem ser observados e comparados a partir da Figura 1, a seguir.

Figura 1: Potencialidades em relação à usabilidade do Moodle

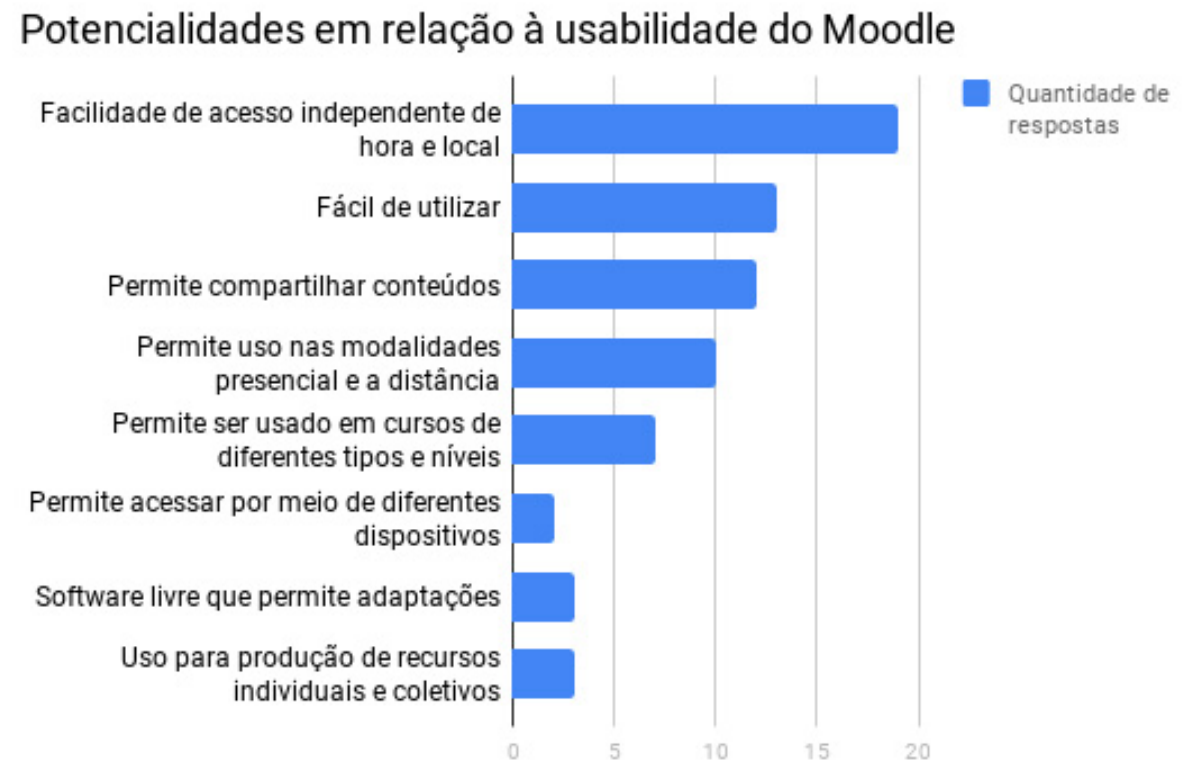

Fonte: Elaboração dos autores (2018).

Outro aspecto que foi destacado pelos estudantes, refere-se às possibilidades de interação que o Moodle permite. A interação pode ser definida como a forma pela qual professor/estudante e estudante/material didático se comunicam, interagem entre si.

A Figura 2 expõe as principais potencialidades destacadas e a partir dela podemos inferir que os discentes concordam que o moodle permite a interação entre os agentes envolvidos (professores e alunos) por meio de comunicação síncrona e assíncrona. Além disso, o fórum de discussão (ferramenta utilizada para a comunicação no AVEA por meio de discussões assíncronas que podem acontecer durante um longo período de tempo) foi destacado como um recurso "ótimo" para compartilhamento de informações e também para a integração entre professor e estudante e entre os próprios estudantes. Por fim, com menor quantidade, mas também relevante, destacou-se a possibilidade de interagir colaborativamente mas também de modo individualizado, ou seja, embora a plataforma possibilite a interação entre vários agentes, ela também possibilita a atenção individualizada e particular. 
Figura 2: Potencialidades em relação à interação no Moodle

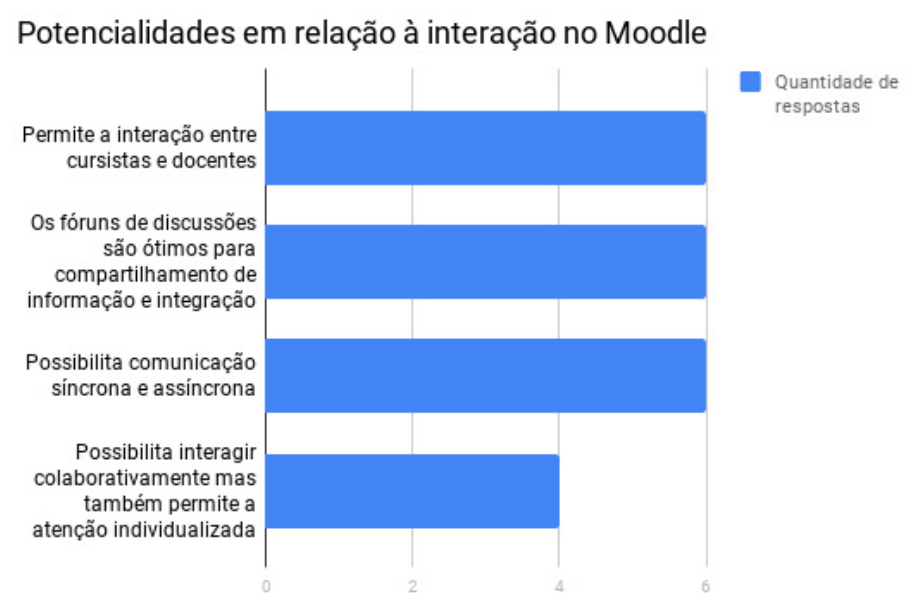

Fonte: Elaboração dos autores (2018).

A Figura 3 evidencia as potencialidades que os discentes observam em relação à aspectos didático-pedagógicos. Neste quesito, destaca-se que o Moodle diversifica os processos de ensino e aprendizagem, inclusive, possibilitando que dois ou mais docentes trabalhem juntos de modo integrado em uma mesma componente curricular. Além disso, identificou-se também que a sua utilização é capaz de aprimorar as habilidades dos docentes em relação ao uso das TICs na Educação. Por fim, foi apontado que a interação entre os colegas por meio da plataforma também contribui com o próprio processo de aprendizagem de cada um.

Figura 3: Potencialidades em relação aos aspectos didático-pedagógicos do Moodle

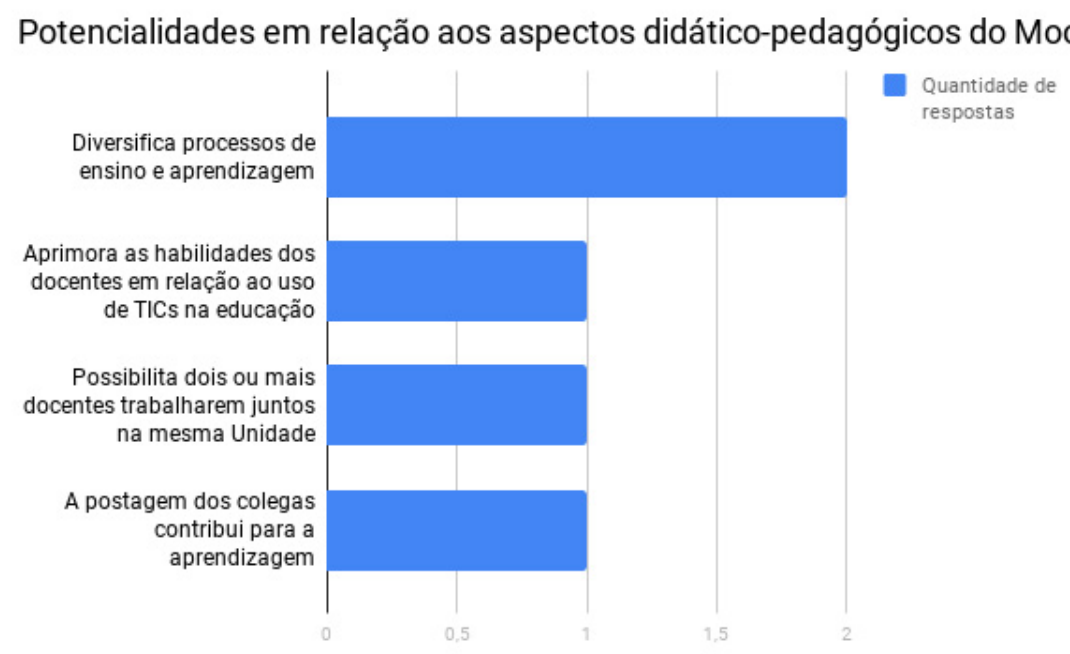

Fonte: Elaboração dos autores (2018). 
Um dos maiores potenciais em relação ao uso de plataforma virtuais de aprendizagem, refere-se à facilidade do registro do processo de ensino e aprendizagem. No Moodle, isso não é diferente e os estudantes observam com positividade esse aspecto como pode ser observado na Figura 4. Conforme relataram, para além da plataforma possibilitar feedback imediato para as tarefas realizadas (algo também típico do universo digital que pode ser, inclusive, automatizado pelos docentes), os discentes ressaltaram que a plataforma permite o registro de notas, de opiniões e também de quem acessa o curso e em que momentos. Além disso, o sistema pode ser configurado para dar alertas sobre prazos e atividades a serem realizadas, permitindo um maior controle e gerenciamento do processo de aprendizagem de cada um. Destacou-se, também, que no Moodle, é possível recuperar atividades realizadas, o que também pode ser muito útil na revisão de conteúdos já estudados.

Figura 4: Potencialidades em relação ao registro e gerenciamento da aprendizagem no Moodle

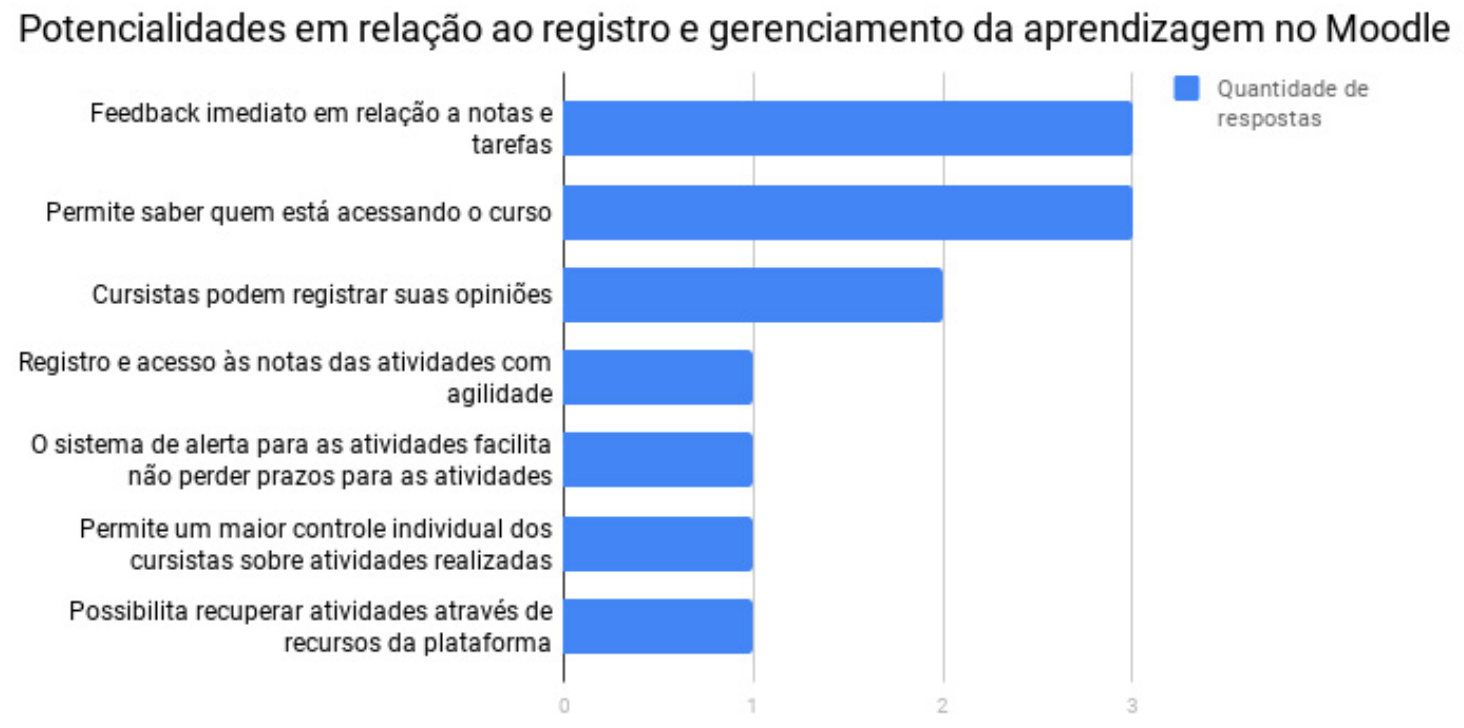

Fonte: Elaboração dos autores (2018).

Por fim, evidencia-se na Figura 5, as potencialidades identificadas em relação à interface e aos recursos disponíveis no Moodle. Os estudantes ressaltam a diversidade de recursos existentes e também a possibilidade de disponibilizar materiais em diferentes formatos e mídias, enfatizando que tais recursos permitem o uso da plataforma como repositório digital. Também destacam que é possível disponibilizar muito conteúdo, com qualidade. 
Figura 5: Potencialidades em relação à interface e recursos disponíveis do Moodle

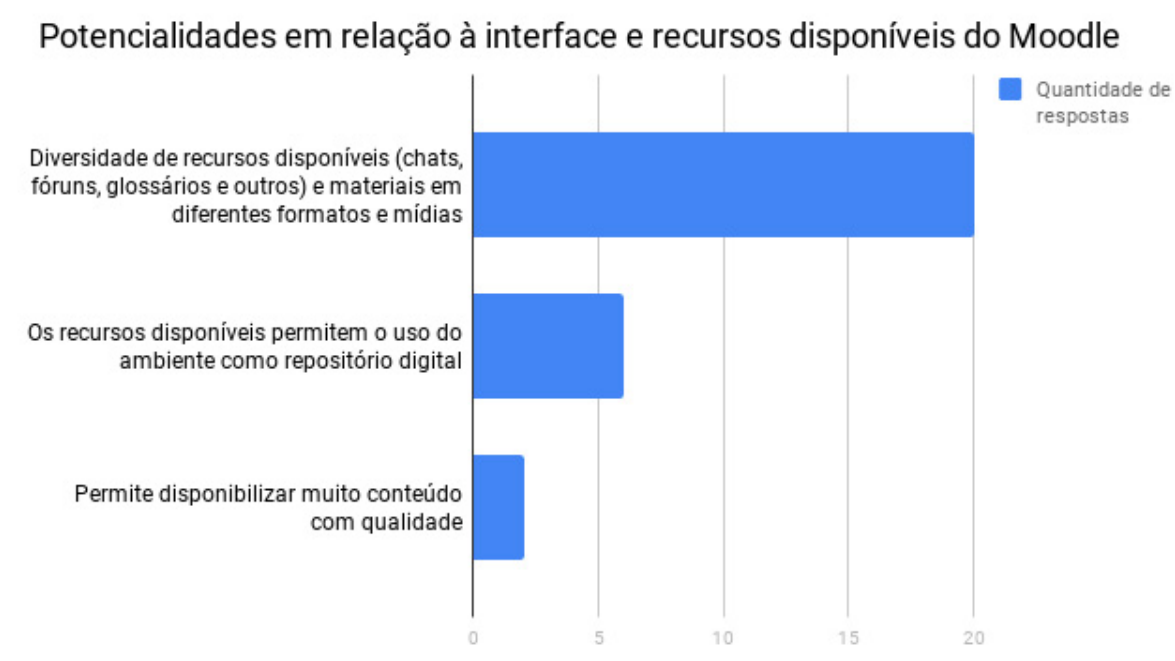

Fonte: Elaboração dos autores (2018).

\section{Considerações finais}

Os resultados apresentados neste artigo compõe um projeto de investigação científica em andamento. Conforme exposto, além das potencialidades, também foram pesquisadas as fragilidades e as proposições de melhoria para AVEAs que utilizam a plataforma Moodle. Acredita-se que a compilação e análise de todos estes aspectos em conjunto possa trazer dados ainda mais consistentes e robustos sobre o tema em estudo. Entretanto, no que tange às potencialidades, convém destacar os aspectos mais enfatizados pelos alunos.

Em relação à sua usabilidade, é o fácil acesso, independente de hora e local, que mais atrai os estudantes nessa plataforma. Quanto à interação, são os fóruns de discussão, a comunicação síncrona e assíncrona e também o trabalho e estudo, ao mesmo tempo, coletivo e individual que mais se destacam. No que se refere aos processos didáticopedagógicos, a potencialidade a ser mais explorada é a diversificação do processo de ensino e aprendizagem. $O$ registro e o gerenciamento da aprendizagem que o Moodle possibilita também é algo que os docentes destacam positivamente na plataforma: possibilidade de saber quem acessa o ambiente em qual momento e de se ter o registro das atividades, das notas e das opiniões é algo que sem dúvida contribui para o maior controle e aproveitamento individual do processo de aprendizagem de cada um. Por fim, destacam-se a diversidade de possibilidades em relação aos recursos, atividades e materiais distribuídos, fatores que contribuem para enriquecer o processo de ensino e aprendizagem, tornando-o mais atrativo e certamente mais eficaz. 
O Moodle é uma plataforma mundialmente conhecida e utilizada nos mais diversos tipos de cursos presenciais e a distância. Nesse cenário, identificar àquilo que os discentes percebem a respeito das potencialidades da plataforma torna-se importante, tanto para outros estudantes quanto para todos aqueles que planejam e oferecem cursos utilizando este tipo de recurso. Tendo sempre em mente, é claro, que tudo aquilo que uma plataforma disponibiliza é relevante e merece ser pontuado, entretanto, é a criatividade, a qualidade dos materiais e a proposta pedagógica adotada que serão determinantes em um processo de ensino e aprendizagem.

\section{Referências}

ABED - Associação Brasileira de Educação a Distância. Censo EAD.BR: relatório analítico da aprendizagem a distância no Brasil 2016. Curitiba: InterSaberes, 2017. AGÊNCIA ESTÚDIO SITE. Quais são os meios virtuais utilizados por EaD. Rio de Janeiro: [s.n], 2017. Disponível em: . Acesso em 18 mai. 2018.

FILATRO, A. Design Instrucional na Prática. São Paulo: Pearson Education do Brasil, 2008.

GIL, A. C. Métodos e técnicas de pesquisa social. São Paulo: Atlas, 2008.

GILLHAM, B. Developing a questionnaire. London: Continuum, 2000.

MARCONI, M. A.; LAKATOS, E. M. Técnicas de pesquisa: planejamento e execução de pesquisas, amostragens e técnicas de pesquisa, elaboração, análise e interpretação dos dados. São Paulo: Atlas, 2010.

OLIVEIRA. E., DE NARDIN, A.AC. O uso do Moodle como suporte às atividades de ensino/aprendizagem presencial em cursos técnicos integrados. A Jornada Nacional de Educação. Educação: Territórios e Saberes, 2012. Disponível em: . Acesso em 18 mai. 2018.

PRIBERAM. "Potencialidade". Dicionário Priberam da Língua Portuguesa [em linha], 2008-2013, Disponível em: . Acesso em 17 abr.

2018.

RODINEY, M. As Tic's no contexto da ead: limites e possibilidades. Educação - Brasil Escola. 2018. Disponível em: <https://brasilescola.uol.com.br/educacao/as-tics-nocontexto-ead-limites-possibilidades.htm>. Acesso em: 23 jul. 2018.

SCHUELTER, G.; BLEICHER, S.; MELLO, C. MOODLE COMO AMBIENTE VIRTUAL DE APOIO A MEDIAÇÃO PEDAGÓGICA: FRAGILIDADES PERCEBIDAS PELO USUÁRIO, CINAHPA | 2017 - Congresso Internacional de Ambientes Hipermídia para Aprendizagem, Blucher Design Proceedings, Volume 3, 2017, p. 508-520. Disponível em: . Acesso em 15 mar. 2018.

SILVA, R. S. da. Ambientes Virtuais e Multiplataformas online na EaD. São Paulo: Novatec Editora, 2015. 